\title{
Infection Control Practices at the Dental Clinics in Jeddah, Saudi Arabia
}

\author{
Zuhair S Natto (10) \\ Mohammed Muslih Alshehri \\ Faisal Khalid Alghamdi \\ Department of Dental Public Health, \\ Faculty of Dentistry, King Abdulaziz \\ University, Jeddah, Saudi Arabia
}

Purpose: The aims of this study were to determine the rate of compliance of infection control and estimate the incidence of COVID-19 in dental clinics in Jeddah, Saudi Arabia. Materials and Methods: This is an ecological correlational study of randomly sampled dental clinics in the city of Jeddah. The 32-question survey used in the study was constructed based on the infection control guidelines/protocols during the COVID-19 pandemic released by the ADA, CDC, and SMOH. A sample of clinics from a dental clinic list in Jeddah city, using a simple random technique.

Results: Fifty-three dental clinics consented to participate in our study, while ten refused. Most of the dental clinics checked their patients' temperature (30.2\%) and strictly required them to wear a surgical mask before entering the clinic (58.5\%). Glove, gown, and face mask were the most common methods of infection control used during all dental procedures (98.1\%, 96.2\%, and $94.3 \%$, respectively). Moreover, the incidence of COVID-19 was the highest among receptions/security $(18.70 \%)$, followed by nurses $(14.3 \%)$ and dentists $(11.79 \%)$.

Conclusion: As the incidence of COVID-19 among dental staff will continue to increase in the future, it is highly recommended that infection control guidelines are followed in all dental clinics.

Keywords: COVID-19, infection control, incidence, dental clinics, Saudi Arabia

\section{Introduction}

The outbreak of coronavirus in 2019 (COVID-19) was identified as a pandemic by the World Health Organization (WHO) on January 30, 2020. ${ }^{1}$ COVID-19 is an illness initiated by severe acute respiratory syndrome coronavirus 2 (SARS-CoV $-2)^{2}$ that originated in Wuhan City, Hubei Province, China, and spread throughout the world via contaminated subjects and airborne transmission. ${ }^{3,4}$ Over 4.7 million deaths have occurred due to COVID-19 up to September 22, 2021. ${ }^{5}$

All health practitioners who potentially come into contact with COVID-19 patients are at risk of infection. ${ }^{6}$ This includes dentists practicing dentistry in pandemic areas, especially when dealing with asymptomatic or pre-symptomatic patients. ${ }^{7}$ In addition, airborne transmission dynamics inside hospitals creates further risk of infection. ${ }^{8,9}$

Dental practitioners are at high risk of facing diseases and infections due to their close contact with patients' oral cavity and exposure to aerosols that might potentially contain a high number of bacteria and viruses. ${ }^{10}$ Several protective measures and infection control protocols have accordingly been suggested to protect dental practitioners from infection. ${ }^{9}$
Correspondence: Zuhair S Natto Department of Dental Public Health, Faculty of Dentistry, King Abdulaziz University, Jeddah, Saudi Arabia

Tel +966503620037

Email znatto@kau.edu.sa 
The current pandemic necessitates dentists' strict adherence to established guidance to maintain the safety of practitioners, staff members, and patients. By following the infection control guidelines provided by the American Dental Association (ADA), the Centers for Disease Control and Prevention (CDC), or the Saudi Ministry of Health $(\mathrm{SMOH})$, the risk of disease transmission and increased precaution measures can be substantially minimized. ${ }^{2,10,11}$ However, COVID-19 continues to be prevalent in the dental field worldwide, particularly in Saudi Arabia. Moreover, there is limited information about the extent and nature of dental clinics' adherence to the modified infection control protocols to minimize the spread of COVID-19 infection. Therefore, this study aims to determine the rate of overall compliance with infection control, compare between public and private clinics in infection control practice, and estimate the incidence of COVID-19 in dental clinics in Jeddah, Saudi Arabia.

\section{Materials and Methods}

This is an ecological correlational study of a random sample of dental clinics in Jeddah city, Saudi Arabia, which was conducted between November 15 and December 18, 2020. During this time period, the COVID-19 vaccine was not yet available in Saudi Arabia. Any dental center/polyclinic was eligible for inclusion in the study if they signed the consent form. The study was approved by the ethics committee at the Faculty of Dentistry, King Abdulaziz University (\#122-11-20), and STROBE Statement for observational studies was followed. All participants (dental clinics) were informed about the purpose of the study, and that they all provided informed consent.

\section{Survey}

A 32-question questionnaire was constructed for this research based on the infection control guidelines/ protocols addressing the COVID-19 pandemic that were released by $\mathrm{ADA}, \mathrm{CDC}$, and $\mathrm{SMOH}$. The survey took about 9-10 minutes to complete and was validated by three experts in infection control (contents validation) and three clinics (face validation). The validated survey was divided into several parts, consisting of the type of clinic; its infection prevention and control efforts before attending to the patient (15 questions), during any dental procedure ( 9 questions), and after dismissing the patient (7 questions); and the total number of dental clinic staff and the self-reported number of individuals diagnosed with SARS-CoV-2 test (confirmed case).

\section{Sample Size and Statistical Analysis}

This is a pilot study for which we randomly selected around one-third (53) clinics from a list of dental clinics in Jeddah city with 159 dental clinics and centers, using a simple random sampling technique. Descriptive statistics (frequency and percentage) was used. Chi-square and Fischer's tests were used to compare between different variables, such as type of institute governmental vs private and all other variables. $\mathrm{P}$ value $<0.05$ was considered statistically significant. All analyses were performed using SPSS V.26 for Windows (IBM).

\section{Results}

Fifty-three dental clinics agreed to participate in our study after excluding ten clinics in which they refused to participate, stating the unavailability of staff to answer the questions as the reason for their refusal.

These clinics contained 1087 individual staff members. Dentists comprised the largest proportion (45.3\%), followed by nurses (39.3\%), reception/security staff $(11.3 \%)$, and dental lab technicians (Table 1). The incidence of COVID-19 was the highest among reception/

Table I Prevalence of COVID-19 Among Dental Clinics

\begin{tabular}{|c|c|c|c|c|c|}
\hline \multirow[t]{3}{*}{ Types of Dental Work } & \multirow[t]{2}{*}{ Overall } & \multicolumn{2}{|c|}{$\begin{array}{l}\text { Diagnosed with COVID-19 Diagnosed COVID-19 in the } \\
\text { Selected Clinics N (\%) }\end{array}$} & \multirow[t]{3}{*}{$\mathbf{X}^{2}$ Statistics } & \multirow[t]{3}{*}{$\boldsymbol{p}$ value $* * *$} \\
\hline & & Yes & No & & \\
\hline & $\mathbf{N}(\%) *$ & $\mathbf{N}(\%)^{* *}$ & $\mathbf{N}(\%) * *$ & & \\
\hline Dentist & $492(45.3)$ & $58(11.79)$ & $434(88.21)$ & 6.144 & 0.105 \\
\hline Nurses & $427(39.3)$ & $61(14.29)$ & $366(85.7 I)$ & & \\
\hline Lab technician & $45(4.1)$ & $3(6.67)$ & $42(93.33)$ & & \\
\hline Receptions/security & $123(11.3)$ & $23(18.70)$ & $100(81.3)$ & & \\
\hline Total & $1087(100)$ & $143(13.16)$ & $944(86.84)$ & & \\
\hline
\end{tabular}

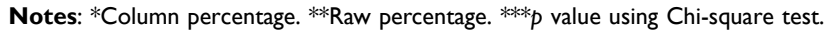


security staff (18.70\%), followed by nurses (14.3\%) and dentists $(11.79 \%)$. However, the result was not statistically significant $(p=0.105)$.

The majority of participating dental centers/polyclinics were in the private sector $(69.8 \%)$. Most clinics had an estimated average of one appointment every 30 minutes (30.2\%), although some had an appointment every ten minutes (Table 2). The majority of the private clinics had 30 minutes, while the public clinics had 60 minutes appointment $(p=0.001)$. Most of the clinics checked the patients' temperature at the clinic entrance $(30.2 \%)$ and used an infrared thermal sensor (20.8\%). Most clinics strictly required staff to wear a surgical mask before entering the dental clinic (58.5\%), maintain an interpersonal distance of at least 2 meters (77.4\%), and use hand sanitizer before meeting with any patient $(77.4 \%)$. However, it seems that public clinics are more restricted regarding the interpersonal distance compared with the private clinics $(p<0.001)$.
Glove, gown, and face mask were the most common infection control efforts used during any dental procedure (98.1\%, 96.2\%, and 94.3\%, respectively) (Table 3). Some clinics allowed for overlapping dental appointments (double-booked) (35.8\%). Private clinics are more restricted regarding the double booked appointment compared with the public clinics $(p=0.042)$. The estimated time for any procedure was less than 30 minutes $(43.4 \%)$. The preferred method of limiting the spread of aerosols was partial isolation $(69.8 \%)$ followed by rubber dam (18.9\%), $p$ value $=0.023$, and 0.039 , respectively.

Disinfecting the clinic; changing gloves, mask, and gown; and washing hands after dismissing each patient was the most common method of infection control (20.8\%), followed by disinfecting the clinic and changing gloves only $(17.0 \%)$ or hand washing $(17.0 \%)$ (Table 4$)$. However, it was not statistically significant between public and private clinics $(p=0.334)$. The length of time between each hand-washing action was less than 20 minutes (84.9\%).

Table 2 Frequency and Percentage of Infection Control Practice Before Any Dental Procedure

\begin{tabular}{|c|c|c|c|c|c|}
\hline Infection Prevention and Control Efforts & $\begin{array}{l}\text { Total } \\
\mathrm{N}=53 \\
\mathrm{~N}(\%)\end{array}$ & $\begin{array}{c}\text { Private } \\
\mathbf{N}=37 \\
\mathbf{N}(\%)\end{array}$ & $\begin{array}{l}\text { Public } \\
\text { N=16 } \\
\text { N (\%) }\end{array}$ & $\begin{array}{c}\mathbf{X}^{2} \\
\text { Statistics }\end{array}$ & $p$ value* \\
\hline Type & & & & & NA \\
\hline - Governmental & $16(30.2)$ & $37(100)$ & - & & \\
\hline - Private & $37(69.8)$ & - & $16(100)$ & & \\
\hline Estimated average length of the appointment & & & & 19.202 & $0.001 * *$ \\
\hline - 90 minutes & $5(9.4)$ & $2(5.4)$ & $3(18.8)$ & & \\
\hline - 60 minutes & $9(13.2)$ & $2(5.4)$ & $5(31.2)$ & & \\
\hline - 45 minutes & $3(5.7)$ & 0 & $3(18.8)$ & & \\
\hline - 30 minutes & $16(32.1)$ & $13(35.1)$ & $4(25)$ & & \\
\hline - 25 minutes & $\mathrm{I}(\mathrm{I} .9)$ & $\mathrm{I}(2.7)$ & 0 & & \\
\hline - 20 minutes & $3(5.7)$ & $2(5.4)$ & $I(6.2)$ & & \\
\hline - 15 minutes & $7(13.2)$ & $7(18.9)$ & 0 & & \\
\hline - 10 minutes & $9(18.9)$ & $10(27.0)$ & 0 & & \\
\hline Actively check temperature in the clinic entry & $51(96.2)$ & $35(94.6)$ & $16(100)$ & 1.000 & 0.903 \\
\hline Checking body temperature using cameras infrared thermal sensors & II (20.8) & $8(21.6)$ & $3(18.8)$ & 0.056 & 0.813 \\
\hline $\begin{array}{l}\text { Postpone dental appointment for about } 2 \text { weeks if patients had fever (38C) } \\
\text { respiratory symptoms or need elective treatment }\end{array}$ & $12(22.6)$ & $6(16.2)$ & $6(37.5)$ & 2.889 & 0.089 \\
\hline Patients should be wear a surgical mask before come to the dental clinics & $31(58.5)$ & $2 I(56.8)$ & 14(87.5) & 4.707 & $0.030 * *$ \\
\hline Patients in the waiting room respected the interpersonal distance $(\geq 2 \mathrm{~m})$ & $33(62.3)$ & $36(97.3)$ & $8(50.0)$ & 17.724 & $<0.001 * *$ \\
\hline $\begin{array}{l}\text { Patients must always wear a surgical mask inside the dental center } \\
\text { unaccompanied by partners relatives. }\end{array}$ & $4 I(77.4)$ & $6(16.2)$ & $6(37.5)$ & 2.889 & 0.089 \\
\hline Operators must sanitize their hands before seeing any patient. & $4 \mid(77.4)$ & $26(70.3)$ & $15(93.8)$ & 3.516 & 0.061 \\
\hline
\end{tabular}

Notes: * $p$ value using Chi-square or Fischer's tests $*^{*} p$ value $<0.05$. 
Table 3 Frequency and Percentage of Infection Control Practice During Any Dental Procedure

\begin{tabular}{|c|c|c|c|c|c|}
\hline Infection Prevention and Control Efforts & $\begin{array}{l}\text { Total } \\
N=53 \\
\text { N (\%) }\end{array}$ & $\begin{array}{c}\text { Private } \\
\begin{array}{c}\text { N=37 N } \\
\text { (\%) }\end{array}\end{array}$ & $\begin{array}{c}\text { Public } \\
\text { N=16 N } \\
\text { (\%) }\end{array}$ & $\begin{array}{c}\mathbf{X}^{2} \\
\text { Statistics }\end{array}$ & $p$ value* \\
\hline \multicolumn{6}{|l|}{ Protection used during dental procedures the following } \\
\hline - Glove & $52(98.1)$ & $36(96.3)$ & $16(100)$ & 1.000 & 0.903 \\
\hline - Gown & 51 (96.2) & $35(94.6)$ & $16(100)$ & 1.000 & 0.764 \\
\hline - Face Mask & $50(94.3)$ & $35(94.6)$ & $15(93.8)$ & 0.015 & 0.534 \\
\hline - Face Shield & $24(45.3)$ & I7(45.9) & $7(43.8)$ & 0.022 & 0.883 \\
\hline - Google & $10(18.9)$ & $6(16.2)$ & $4(25.0)$ & 0.563 & 0.453 \\
\hline - Head cover & $6(11.3)$ & $4(10.8)$ & $2(12.5)$ & 0.032 & 0.858 \\
\hline $\begin{array}{l}\text { Cloth face coverings should not be worn instead of a respirator or face } \\
\text { mask. }\end{array}$ & $29(54.7)$ & $19(51.4)$ & $10(62.5)$ & 0.560 & 0.454 \\
\hline $\begin{array}{l}\text { Patients can wait outside the dental facility where they can be contacted by } \\
\text { mobile phone when it is their turn for dental care. }\end{array}$ & $23(43.4)$ & $13(35.1)$ & $10(62.5)$ & 3.405 & 0.065 \\
\hline \multicolumn{6}{|l|}{ Mobile phone when it is their turn for dental care } \\
\hline No overlapping dental appointments. & $34(64.2)$ & $27(72.9)$ & $7(43.8)$ & 4.148 & $0.042 * *$ \\
\hline $\begin{array}{l}\text { The estimated time of any procedure } \\
\text { - Depend on the case }\end{array}$ & $10(18.9)$ & $8(21.6)$ & $2(12.5)$ & 0.713 & 0.700 \\
\hline Less than 30 & $23(43.4)$ & $16(43.2)$ & $7(43.8)$ & & \\
\hline More than 30 & $20(37.7)$ & $13(35.1)$ & $7(43.8)$ & & \\
\hline Minimizing the use of intraoral $X$-ray techniques & $48(90.6)$ & $37(100)$ & II (68.8) & 0.001 & $0.003 * *$ \\
\hline $\begin{array}{l}\text { The clinic door must be closed during interventions to avoid any aerosol } \\
\text { spreading }\end{array}$ & $43(81.1)$ & $32(86.5)$ & II (68.8) & 2.295 & 0.129 \\
\hline \multicolumn{6}{|c|}{ The used method to minimize the spreading of aerosols and potentially infected biologic material if applicable } \\
\hline \multicolumn{6}{|l|}{ Biologic material if applicable } \\
\hline - Rubber dam & $10(18.9)$ & $4(10.8)$ & 6(37.5) & 5.198 & $0.023 * *$ \\
\hline - Partial isolation & $37(69.8)$ & 29(78.4) & $8(50.0)$ & 4.268 & $0.039 * *$ \\
\hline - None & $6(11.3)$ & $4(10.8)$ & $2(12.5)$ & 0.032 & 0.859 \\
\hline
\end{tabular}

Notes: ${ }^{*} p$ value using Chi-square or Fischer's tests. ${ }^{* *} p$ value $<0.05$

\section{Discussion}

To our knowledge, our article is the first to calculate the estimated incidence of SARS-CoV-2 infections in dental practice and evaluate the actual infection prevention and control efforts at the level of dental centers in Saudi Arabia during the pandemic. This will be useful in future studies on the dental response to any pandemic and how to protect dental staff and prevent the spread of infection. We have reported the infection incidence of SARS-CoV-2 in Jeddah as $11.79 \%$, which is higher than the figures reported in the US $(0.9 \%),{ }^{12}$ the Netherlands $(0.9 \%),{ }^{13}$ China $(1.1 \%),{ }^{14}$ and Seattle, Washington $(5.3 \%) .{ }^{15}$ This could be due to the fact that the study was conducted at the end of 2020, whereas the other studies were conducted earlier. Moreover, receptions/security were the highest at risk. This could be due to lack of proper knowledge on the infection control guidelines/protocols during the COVID-19 released by SMOH or because receptions/security were not wearing PPE. Receptions/ security are the least likely dental staff in the dental clinics to perform dental procedures. However, the rate of COVID-19 incidence was still high among them as reported in the study. Nonetheless, they are equally exposed to COVID-19.

The responses to our study demonstrate that $96.2 \%$ of the participating dental clinics were checking temperature before entry to the clinic centers have established temperature monitoring, which has been proven as 
Table 4 Frequency and Percentage of Infection Control Practice After Any Dental Procedure

\begin{tabular}{|c|c|c|c|c|c|}
\hline Infection Prevention and Control Efforts & $\begin{array}{c}\text { Total } N=53 \\
N(\%)\end{array}$ & $\begin{array}{c}\text { Private } \mathbf{N}=\mathbf{3 7} \\
\mathbf{N}(\%)\end{array}$ & $\begin{array}{c}\text { Public } \mathbf{N}=16 \\
\mathbf{N}(\%)\end{array}$ & $\begin{array}{c}\mathbf{X}^{2} \\
\text { Statistics }\end{array}$ & $p$ value* \\
\hline $\begin{array}{l}\text { Methods of infection control after patient visit } \\
\text { - Change gloves and hand wash only } \\
\text { - Change gloves only } \\
\text { - Disinfect all the clinic and change gloves } \\
\text { - Change gloves and masks } \\
\text { - Disinfect all the clinic and change gloves, masks, gown, hand wash } \\
\text { - Disinfect all the clinic and change gloves, hand wash } \\
\text { - Change gloves, mask and gown } \\
\text { - Change gloves and gown } \\
\text { - Disinfect all the clinic and change gloves, mask }\end{array}$ & $\begin{array}{c}6(11.3) \\
10(18.9) \\
.9(17.0) \\
4(7.5) \\
11(20.8) \\
9(17.0) \\
2(3.8) \\
1(1.9) \\
1(1.9)\end{array}$ & $\begin{array}{c}4(\mid 0.8) \\
8(2 \mid .6) \\
5(\mid 3.5) \\
4(10.8) \\
6(\mid 6.2) \\
8(21.6) \\
1(2.7) \\
1(2.7) \\
0\end{array}$ & $\begin{array}{c}2(12.5) \\
2(12.5) \\
4(25.0) \\
0 \\
5(3 I .2) \\
I(6.3) \\
I(6.3) \\
0 \\
I(6.3)\end{array}$ & 8.661 & 0.334 \\
\hline $\begin{array}{l}\text { Length of hand hygiene wash between patients } \\
\text { - Less than } 20 \\
\text { - more than } 20\end{array}$ & $\begin{array}{l}45(84.9) \\
8(15.1)\end{array}$ & $\begin{array}{c}31(83.8) \\
6(16.2)\end{array}$ & $\begin{array}{l}14(87.5) \\
2(12.5)\end{array}$ & 0.120 & 0.729 \\
\hline $\begin{array}{l}\text { Patients must remove their masks at the beginning of the } \\
\text { procedure and wear them again at the end }\end{array}$ & $34(64.2)$ & $25(67.6)$ & $9(56.3)$ & 0.622 & 0.430 \\
\hline
\end{tabular}

Note: $* p$ value using Chi-square or Fischer's tests.

effective strategy to prevent infection. ${ }^{16,17}$ Most of the clinics - at least $94 \%$ - were using gloves, masks, and gowns to enhance infection control practices during the dental procedure. However, the combined use of surgical masks and respirators might not follow the current CDC recommendations regarding personal protection. The estimated number of patients, which in June 2020 was at about $70 \%$ of pre-COVID-19 levels, has since continued to steadily increase. ${ }^{18}$ Clinics may require a larger amount of disposable personal protection products for infection control to meet the demands of the rising number of patients; however, the capacity for these products to be provided remains uncertain, depending on their availability and cost. ${ }^{19-23}$

Availability and effectiveness of protection methods is a critical factor for dental health care staff. These methods include sterilization, hand washing, and the use of personal protective equipment. ${ }^{24,25}$ Basic personal protective equipment includes gloves, face masks, gowns, and eye protection goggles, all of which are commonly used in most dental clinics and create a safer environment for dental staff and patients alike. ${ }^{26}$ However, the moderate use of face shields (45\%) has also been noted; the use of face shields has been shown to provide additional protection to the facial area and all potential entry points, such as the mucous membranes of the mouth, eyes, nose, in addition to respiratory protection. ${ }^{27}$ Moreover, the face area is the most contaminated area during dental treatment. A face shield can protect this area from any splashes or spatters of bodily fluids or aerosols generated during dental procedures. ${ }^{28,29}$ For these reasons, the use of face shields is recommended rather than face masks to minimize the spread of COVID-19 and virus exposure in the community. ${ }^{30}$ Therefore, dentists should use face shields as part of their standard personal protection in dental clinics, especially during the pandemic. Moreover, no one reported to use the N95 or PFF2/3 or equivalent mask, which were highly recommended for any dental procedure due to loose fit between the surface of the regular mask and the face. ${ }^{31,32}$

Therefore, dentists should use face shields as part of their standard personal protection in dental clinics, especially during the pandemic. However, these findings contain some limitations. There is a risk of selection bias regarding the participating clinics sample, which might lead to an underestimation of the COVID-19 incidence or severity due to the possibility that the clinics that refused to participate had more COVID-19 cases. Although a simple random sample of all dental clinics helps to minimize this risk of bias, it does not totally exclude it. Also, some dentists may have been asymptomatic and might have had undiagnosed infections. Furthermore, these findings are self-reported, making clinics and staff potentially subject to inaccurate results. However, this is a pilot study, which we can use to build our knowledge for future research. Lastly, this study was 
conducted in Jeddah only which may not represent the whole kingdom of Saudi Arabia.

There is a general sense of lack of sufficient infection control practice at the public dental clinics compared with the private clinics due to daily number of patients, patient preferences, and repeated visits of dental licensing officers to the private clinics. ${ }^{30,33}$ However, we found several items that could be improved overall, such as average length and overlap dental appointment, interpersonal distance, minimizing intra-oral X-rays and methods of infection control. Moreover, the majority of the dental centers were following the guidelines and were comparable to the clinics in Europe and North America. $^{12,34}$ To the statistical significant differences between private versus public did not necessarily reflect better or worse infection control practices since it evaluates the dental center overall and it could varied between clinics at the participated dental center.

\section{Conclusion}

The incidence of COVID-19 among dental staff is about $13 \%$ and will increase more in the future. It is therefore highly recommended that all dental clinics adhere to the infection control guidelines, which will help to reduce the risk of infection spreading both during the delivery of oral healthcare and subsequently throughout the community.

\section{Disclosure}

The authors report no conflicts of interest in this work.

\section{References}

1. World Health Organization. WHO Timeline - COVID-19. Available from: https://www.who.int/news/item/27-04-2020-whotimeline - covid-192020. Accessed January 20, 2021.

2. CDC. Centers for Disease and Prevention Guidance for Dental settings: interim infection prevention and control guidance for dental settings during the coronavirus disease (COVID-19) pandemic; 2020. Available from: https://www.cdc.gov/coronavirus/2019-ncov/hcp/den tal-settings.html. Accessed February 27, 2021.

3. Kissler SM, Tedijanto C, Goldstein E, Grad YH, Lipsitch M. Projecting the transmission dynamics of SARS-CoV-2 through the postpandemic period. Science. 2020;368(6493):860-868. doi:10.1126/science.abb5793

4. Alshaeri HK, Natto ZS. A contemporary look at COVID-19 medications: available and potentially effective drugs. Eur Rev Med Pharmacol Sci. 2020;24:9188-9195.

5. Worldmeters. Corona cases. Available from: https://www.world ometers.info/coronavirus/2021. Accessed July 20, 2021.

6. Prather KA, Wang CC, Schooley RT. Reducing transmission of SARS-CoV-2. Science. 2020;368:1422-1424. doi:10.1126/science. abc6197

7. Kutter JS, Spronken MI, Fraaij PL, Fouchier RA, Herfst S. Transmission routes of respiratory viruses among humans. Curr Opin Virol. 2018;28:142-151. doi:10.1016/j.coviro.2018.01.001
8. Harrel SK, Molinari J. Aerosols and splatter in dentistry: a brief review of the literature and infection control implications. JADA. 2004;135:429-437.

9. Banakar M, Bagheri Lankarani K, Jafarpour D, Moayedi S, Banakar MH, MohammadSadeghi A. COVID-19 transmission risk and protective protocols in dentistry: a systematic review. BMC Oral Health. 2020;20:275. doi:10.1186/s12903-020-01270-9

10. ADA. American Dental Association ADA interim guidance for minimizing risk of COVID-19 transmission. Available from: https://web.archive. org/web/20200506114732/https://www.ada.org/ /media/CPS/Files/ COV-ID/ADA_COVID_Int_Guidance_Treat_Pts.pdf?utm_source=cpsor g\&utm_medium $=$ covid-cps $=$ virus-lp\&utm_content $=$ cv-pm-ebd-interimresponse\&utm_campaign=covid-192020. Accessed March 3, 2020.

11. SMOH. Guidance for providing dental services in governmental and private sector during COVID-19 pandemic; 2020. Available from: https://www.moh.gov.sa/Ministry/MediaCenter/Publications/ Documents/MOH-Guidelines-for-re-opening-June-.pdf: Saudiministryofhealh. Accessed March 3, 2021.

12. Estrich CG, Mikkelsen M, Morrissey R, et al. Estimating COVID-19 prevalence and infection control practices among US dentists. JADA. 2020;151:815-824.

13. Kluytmans-van den Bergh MFQ, Buiting AGM, Pas SD, et al. Prevalence and clinical presentation of health care workers with symptoms of coronavirus disease 2019 in 2 Dutch hospitals during an early phase of the pandemic. JAMA Netw open. 2020;3:e209673.

14. Lai X, Wang M, Qin C, et al. Coronavirus Disease 2019 (COVID-2019) infection among health care workers and implications for prevention measures in a Tertiary Hospital in Wuhan, China. JAMA Netw open. 2020;3:e209666. doi:10.1001/jamanetwo rkopen.2020.9666

15. Mani NS, Budak JZ, Lan KF, et al. Prevalence of COVID-19 infection and outcomes among symptomatic healthcare workers in Seattle, Washington. Clin Infect Dis. 2020;71:2702-2707. doi:10.1093/cid/ ciaa761

16. Berdahl CT, Nguyen AT, Diniz MA, et al. Using body temperature and variables commonly available in the EHR to predict acute infection: a proof-of-concept study showing improved pretest probability estimates for acute COVID-19 infection among discharged emergency department patients. Diagnosis (Berl). 2021. doi:10.1515/dx-2021-0020

17. Hsiao SH, Chen TC, Chien HC, Yang CJ, Chen YH. Measurement of body temperature to prevent pandemic COVID-19 in hospitals in Taiwan: repeated measurement is necessary. $J$ Hosp Infect. 2020;105:360-361. doi:10.1016/j.jhin.2020.04.004

18. Institute HP. COVID-19 economic impact: survey results; 2021. Available from: https://www.ada.org/en/science-research/healthpolicy-institute/covid-19-dentists-economic-impact/survey-results: AmericanDentalAssociation. Accessed March 2, 2021.

19. Natto ZS. Dental students' knowledge and attitudes about electronic cigarettes: a cross-sectional study at One Saudi University. $J$ Dent Educ. 2020;84:27-33. doi:10.21815/JDE.019.162

20. Natto ZS, Alshaeri HK. Are Saudi healthcare students aware of COVID-19, and do they behave safely during viral outbreaks? Niger J Clin Pract. 2021;24:406-411. doi:10.4103/njcp.njcp_259_20

21. Natto ZS, Alshaeri HK. Characteristics of first cases of coronavirus disease 2019 and the effort to prevent the early spread of COVID-19 in Saudi Arabia. Risk Manag Healthc Policy. 2021;14:315-321. doi:10.2147/RMHP.S278394

22. Natto ZS, Parashis A, Steffensen B, et al. Efficacy of collagen matrix seal and collagen sponge on ridge preservation in combination with bone allograft: a randomized controlled clinical trial. $J$ Clin Periodontol. 2017;44(6):649-659. doi:10.1111/jcpe.12722

23. ALHarthi SS, Natto ZS, Midle JB, et al. Association between time since quitting smoking and periodontitis in former smokers in the National Health and Nutrition Examination Surveys (NHANES) 2009 to 2012. J Periodontol. 2019;90(1):16-25. doi:10.1002/ JPER.18-0183 
24. DePaola LG. Managing the care of patients infected with bloodborne diseases. JADA. 2003;134:350-358.

25. Harte JA. Standard and transmission-based precautions: an update for dentistry. JADA. 2010;141:572-581.

26. Molinari JA. Dental infection control at the year 2000: accomplishment recognized. JADA. 1999;130:1291-1298.

27. Lindsley WG, Noti JD, Blachere FM, Szalajda JV, Beezhold DH. Efficacy of face shields against cough aerosol droplets from a cough simulator. J Occup Environ Hyg. 2014;11:509-518. doi:10.1080/ 15459624.2013.877591

28. Nejatidanesh F, Khosravi Z, Goroohi H, Badrian H, Savabi O. Risk of contamination of different areas of dentist's face during dental practices. Int J Prev Med. 2013;4:611-615.

29. Roberge RJ. Face shields for infection control: a review. J Occup Environ Hyg. 2016;13:235-242. doi:10.1080/15459624.2015. 1095302

30. Perencevich EN, Diekema DJ, Edmond MB. Moving personal protective equipment into the community: face shields and containment of COVID-19. JAMA. 2020;323(22):2252-2253. doi:10.1001/ jama.2020.7477
31. Food and Drug Administration. N95 respirators, surgical masks, and face masks, 2020. Available from: https:/www.fda.gov/medicaldevices/personal-protective-equipment-infection-control/n95-

respirators-surgical-masks-and-face-masks\#s2. Accessed March 2, 2021.

32. Souza AF, de Arruda JAA, Costa FPD, et al. Safety protocols for dental care during the COVID-19 pandemic: the experience of a Brazilian hospital service. Braz Oral Res. 2021;35:e070. doi:10.1590/1807-3107bor-2021.vol35.0070

33. Al-Rabeah A, Moamed AG. Infection control in the private dental sector in Riyadh. Ann Saudi Med. 2002;22:13-17. doi:10.5144/02564947.2002.13

34. Becker K, Gurzawska-Comis K, Brunello G, Klinge B. Summary of European guidelines on infection control and prevention during COVID-19 pandemic. Clin Oral Implants Res. 2021. doi:10.1111/ clr. 13784
Journal of Multidisciplinary Healthcare

\section{Publish your work in this journal}

The Journal of Multidisciplinary Healthcare is an international, peerreviewed open-access journal that aims to represent and publish research in healthcare areas delivered by practitioners of different disciplines. This includes studies and reviews conducted by multidisciplinary teams as well as research which evaluates the results or conduct of such teams or healthcare processes in general. The journal

\section{Dovepress}

covers a very wide range of areas and welcomes submissions from practitioners at all levels, from all over the world. The manuscript management system is completely online and includes a very quick and fair peer-review system. Visit http://www.dovepress.com/testimonials. php to read real quotes from published authors. 